\title{
Cross-Sectional Study
}

National Cancer Institute

\section{Source}

National Cancer Institute. Cross-Sectional Study. NCI Thesaurus. Code C53310.

A study in which participants are examined once for a characteristic, such as disease, at a single point in time. 